\title{
Scavenger Receptor Class B Member 1 Independent Uptake of Transthyretin by Cultured Hepatocytes Is Regulated by High Density Lipoprotein
}

\author{
Kelly A. Landers, ${ }^{1}$ Michael C. d'Emden, ${ }^{2,3}$ and Kerry Richard $\mathbb{D}^{1,3,4}$ \\ ${ }^{1}$ Conjoint Internal Medicine Laboratory, Chemical Pathology, Pathology Queensland, Queensland Health, Herston, \\ QLD 4029, Australia \\ ${ }^{2}$ Department of Endocrinology and Diabetes, Royal Brisbane and Women's Hospital, Herston, QLD 4029, Australia \\ ${ }^{3}$ School of Medicine, University of Queensland, Herston, QLD 4029, Australia \\ ${ }^{4}$ School of Biomedical Sciences, Queensland University of Technology, Brisbane, QLD 4000, Australia
}

Correspondence should be addressed to Kerry Richard; kerry.richard@qimrberghofer.edu.au

Received 9 April 2019; Revised 31 May 2019; Accepted 4 June 2019; Published 18 June 2019

Academic Editor: Matti Jauhiainen

Copyright (C) 2019 Kelly A. Landers et al. This is an open access article distributed under the Creative Commons Attribution License, which permits unrestricted use, distribution, and reproduction in any medium, provided the original work is properly cited.

\begin{abstract}
Thyroid hormone (thyroxine, T4) is essential for the normal function of all cell types and is carried in serum bound to several proteins including transthyretin. Recently, evidence has emerged of alternate pathways for hormone entry into cells that are dependent on hormone binding proteins. Transthyretin and transthyretin bound T4 are endocytosed by placental trophoblasts through the high-density lipoprotein receptor, Scavenger Receptor Class B Type 1 (SR-B1). High density lipoprotein (HDL) affects the expression and function of SR-B1 in trophoblast cells. SR-B1 is also expressed in hepatocytes and we sought to determine if hepatocyte SR-B1 was involved in transthyretin or transthyretin-T4 uptake and whether uptake was affected by HDL. Transthyretin and transthyretin-T4 uptake by hepatocytes is not dependent on SR-B1. HDL treatment reduced SR-B1 expression. However, pretreatment of hepatocytes with HDL increased uptake of transthyretin-T4. Knockdown of SR-B1 expression using siRNA also increased transthyretin-T4 uptake. Coaddition of HDL to transthyretin uptake experiments blocked both transthyretin and transthyretin-T4 uptake. Hepatocyte uptake of transthyretin-T4 uptake is influenced by, but is not dependent on, SR-B1 expression. HDL also decreases transthyretin-T4 uptake and therefore diet or drugs may interfere with this process. This suggests that multiple lipoprotein receptors may be involved in the regulation of uptake of transthyretin-T4 in a cell-type specific manner. Further study is required to understand this important process.
\end{abstract}

\section{Introduction}

Transfer of thyroid hormone into cells is critical for normal physiology. Free thyroid hormone is known to enter cells through specific cell surface transport proteins, including monocarboxylate transporters 8 and 10, and organic anion transporting polypeptides [1]. For many years this uptake of unbound thyroid hormone was assumed to be the only relevant mechanism, supporting the free hormone hypothesis [2].

The thyroid hormone binding protein transthyretin (TTR) is also produced by and endocytosed by many different cell types [3-5]. Liver is the major site of production and secretion of serum TTR and is also its main site of catabolism
[6]. TTR is the major protein found in human cerebrospinal fluid (25\% of total protein) and is synthesized and secreted into CSF by choroid plexus epithelial cells [7]. TTR is then endocytosed by Megalin (LRP2)[4], an endocytic multiligand receptor of the low-density lipoprotein (LDL) receptor family, in brain astrocytes $[8,9]$ with uptake increased in the presence of thyroid hormone in the form of thyroxine (T4). TTR synthesis by choroid plexus is essential for distribution of T4 around the brain [10]. TTR uptake by kidney is also mediated by Megalin expressed in the epithelium of renal proximal tubules. TTR uptake by liver is also thought to be via a lipoprotein receptor [5]; however the specific receptor has not yet been identified. TTR is a carrier of thyroid hormone; it transports retinol through its association with 
retinol binding protein; it binds many endo- and xenobiotics (in particular endocrine disrupting chemicals); it is involved in the regulation of astrocytic glycolysis [11]; and mutations in TTR lead to hereditary amyloidosis [12].

TTR is also synthesized by human placenta [13] and its endocytosis by trophoblasts [3] is enhanced by the presence of T4 [3]. This receptor mediated uptake of transthyretin bound to thyroxine (TTR-T4) into placental trophoblasts is dependent on expression of Scavenger Receptor Class B Type 1 (SR-B1) which is also a high-density lipoprotein (HDL) receptor [14]. TTR-T4 uptake by trophoblasts was increased by pretreatment of cells with HDL for four hours, and HDL also competes with TTR for uptake through SR-B1 [14].

Given the importance of T4 for liver cell function, the importance of liver in both TTR and T4 metabolism, and strong expression of SR-B1 in hepatocytes [15], we sought to determine if SR-B1 and/or HDL are important in the regulation of hepatocyte TTR and TTR-T4 uptake.

\section{Methods}

2.1. Reagents. Transthyretin (Prealbumin from human serum) was purchased as a lyophilised powder from Sigma Aldrich, Victoria, Australia. High-density lipoprotein (HDL) from human plasma was purchased as a solution from Sigma Aldrich, Victoria, Australia. Unless otherwise stated reagents were from Sigma Aldrich, Victoria, Australia.

2.2. Cell Culture. The human hepatocyte cell line, HepG2 (HB-8065), was obtained from the American Type Culture Collection (ATCC) (VA, USA) and maintained in Dulbecco's Modified Eagle’s Medium (DMEM) (Sigma, Castle Hill, NSW, Australia) $/ 10 \%$ FBS in a humidified atmosphere of $95 \%$ air and $5 \% \mathrm{CO}_{2}$.

2.3. Knockdown of SR-B1 Expression Using Mission esiRNA. Knockdown of SR-B1 was achieved using MISSION esiRNA (Sigma) in combination with Lipofectamine RNAiMAX transfection reagent (Thermo Fisher) as per manufacturer's instructions and as previously described [14]. Kif1la esiRNA was used as a positive transfection control and EGFP esiRNA as a mock control. Cells were cultured in 24-well plates (50 000 cells/well) and grown overnight. After 24 hours, culture medium was replaced with antibiotic free medium. Subsequently, $1.2 \mu \mathrm{M}$ MISSION esiRNA in Opti-MEM and 0.04\% (V/V) Lipofectamine RNAiMAX in Opti-MEM were incubated together before adding to cells for 24 hours. This transfection process was repeated after 24 hours. Cells were used in experiments 24 hours after the final transfection.

2.4. Alexa-TTR Labelling. Purified native human TTR protein was labelled using an Alexa Fluor ${ }^{\circledR} 568$ Protein Labelling Kit (Life Technologies, VIC, Australia). Briefly, $1 \mathrm{ml}$ of 2 $\mathrm{mg} / \mathrm{ml}$ purified TTR protein was incubated with Alexa Fluor ${ }^{\circledR}$ 568 reactive dye for 2 hours at room temperature. Then Alexa Fluor 568 labelled-TTR (Alexa-TTR) was purified through a Bio-Gel P-6 Gel column (BioRad, CA, USA). To determine the concentration of labelled TTR and the degree of fluorescent labelling, the conjugate solution was measured at $280 \mathrm{~nm}$ and $540 \mathrm{~nm}$ in a NanoDrop 2000 spectrophotometer (Thermo Scientific, NC, USA).

2.5. Quantification of Alexa568-TTR Uptake. HepG2 cells ( 50,000 cells/well) were cultured on 24 -well plates for 48-72 hours. Following serum starvation for 4 hours, cells were incubated with $1 \mathrm{uM}$ Alexa568-TTR $\pm 10 \mu \mathrm{M}$ T4 as previously published [3] and imaged using an IncuCyte $\mathrm{ZOOM}^{\mathrm{TM}}$ live cell-imaging system (Essen BioScience, MI, USA) with Phase and Red channels and scanned at 2-3 hours' intervals for up to 48 hours. IncuCyte ZOOM software was used to quantify the red objects in 9 nonoverlapping images per well (the average of these 9 values is equivalent to $n=1$ ). Data were presented as mean number of red objects per image relative to percentage confluence.

2.6. Western Blotting. Twenty $\mu \mathrm{g}$ of total cell lysate was run on NuPAGE Novex Bis-Tris gradient gels (Invitrogen). Proteins were transferred to nitrocellulose and probed using the following antibodies from Sigma: rabbit anti-SR-B1, 1:750, and mouse anti- $\beta$-actin, 1:2000. Blots were developed using a SuperSignal West Femto Kit (Pierce, Scoresby, VIC, Australia) and imaged using a LAS-4000 (Fujifilm, Brookvale, NSW, Australia). Blots were quantified using ImageJ software (NIH).

2.7. Statistical Analysis. Statistical analysis was performed using Microsoft Excel or GraphPad Prism Software (GraphPad Software, Inc., CA, USA). Comparison between groups was determined by one-way ANOVA with Tukey's test or by paired Student's t-test. $\mathrm{P}$ values of $\leq 0.05$ were considered significant.

\section{Results}

3.1. Effect of HDL Treatment on SR-B1 Levels in HepG2 Cells. $\mathrm{SR}-\mathrm{B} 1$ is an HDL receptor and incubation with HDL increases SR-B1 levels in trophoblasts [14]. The normal reference range for serum HDL is 400 to $600 \mathrm{ug} / \mathrm{ml}$ and individuals with HDL values less than $400 \mathrm{ug} / \mathrm{ml}$ are at increased risk of heart disease. We tested whether HDL (0-500 ug/ml) influenced SR-B1 levels in hepatocyte cells. Following four hours in serum free medium, treatment with HDL for 24 hours resulted in significantly decreased SR-B1 levels but the effect was not dose dependent. $250 \mathrm{ug} / \mathrm{ml}$ HDL reduced SR-B1 levels to less than $50 \%$ of control $(\mathrm{p}=0.001, \mathrm{n}=2)$ and $15 \mathrm{ug} / \mathrm{ml}$ HDL reduced SR-B1 levels to $70 \%$ of control $(p=0.04, n=4)$ (Figure 1).

3.2. Uptake of Alexa-TTR in HDL Treated Cells. HDL decreases SR-B1 expression in HepG2 cells but HDL is also transported through SR-B1 and may compete with TTR and TTR \pm T4 uptake through SR-B1 when both HDL and TTR are present together in the uptake medium [14]. We therefore also tested whether coincubation with HDL influences TTR $( \pm$ T4) uptake through SR-B1 in HepG2 cells. We preincubated with either no HDL (untreated) or $500 \mathrm{ug} / \mathrm{ml} \mathrm{HDL}$ (pretreated /normal serum level of HDL) and then coincubated 




(a)

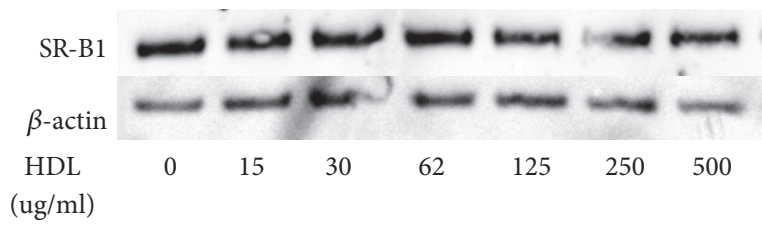

(b)

FIGURE 1: Treatment with high density lipoprotein (HDL) reduces scavenger receptor class B type 1(SR-B1) expression in HepG2 cells. (a) Treatment with $15,62,125,250$, and $500 \mathrm{ug} / \mathrm{ml}$ HDL all significantly reduced protein levels of SR-B1. (b) Representative Western blot showing reduction of SR-B1 levels. Cells were treated with 15-500 ug/ml HDL for 24 hours. Cell lysates were collected and run on 4-12\% Bis-Tris gels, transferred to nitrocellulose, probed with anti-SRB1 (1:750) and anti- $\beta$-Actin (1:2000) antibodies, and developed using enzyme linked chemiluminescence. Protein levels were quantitated using ImageJ software $(* * \mathrm{p}<0.01, * \mathrm{p}<0.05 ; 15-125 \mathrm{ug} / \mathrm{ml}, \mathrm{n}=4$ and $250-500 \mathrm{ug} / \mathrm{ml}, \mathrm{n}=2)$.

with $500 \mathrm{ug} / \mathrm{ml}$ (normal serum level) or $1000 \mathrm{ug} / \mathrm{ml}$ (high serum level) of HDL.

3.2.1. Pretreatment of Cells with HDL. Pretreatment of HepG2 cells with $500 \mathrm{ug} / \mathrm{ml} \mathrm{HDL}$ in serum free medium for 4 hours (orange bars) resulted in no significant change in uptake of Alexa-TTR at 24 hours compared to control (blue bars) (Figures 2(a) and 2(b)). Pretreatment with HDL resulted in increased uptake of Alexa-TTR-T4 at 24 hours (441.1 \pm 39.5 vs. control 344.5 $\pm 9.3, \mathrm{n}=4, \mathrm{p}<0.05$ ) (Figures $2(\mathrm{a})$ and $2(\mathrm{c})$ ). Despite pretreatment with HDL leading to increased uptake of Alexa-TTR-T4 at 24 hours, we were unable to demonstrate any significant changes in SR-B1 protein levels following 4 hours' pretreatment in 500ug/ml HDL (data not shown).

\subsubsection{Coaddition of HDL into the Alexa-TTR Uptake Medium} Results in Decreased Uptake of Alexa-TTR and Alexa-TTR-T4. At 24 hours, coincubation with $500 \mathrm{ug} / \mathrm{ml}$ HDL resulted in significantly reduced uptake of Alexa-TTR in both untreated (blue bars, $194.5 \pm 23.8, \mathrm{n}=4, \mathrm{p}=0.01$ ) and HDL pretreated (orange bars, $230.3 \pm 11.8, \mathrm{p}<0.05$ ) cells when compared to controls (313.3 \pm 20.8 and $415.0 \pm 54.7$, resp., $\mathrm{n}=4) .1000 \mathrm{ug} / \mathrm{ml}$ HDL resulted in significantly decreased uptake of AlexaTTR in HDL pretreated cells only $(219.7 \pm 1.8, \mathrm{n}=4, \mathrm{p}<0.05)$ (Figure 2).

At 24 hours, coincubation with $500 \mathrm{ug} / \mathrm{ml} \mathrm{HDL}$ or $1000 \mathrm{ug} / \mathrm{ml} \mathrm{HDL}$ resulted in significantly reduced uptake of Alexa-TTR-T4 in both untreated and HDL pretreated cells. In untreated cells, $500 \mathrm{ug} / \mathrm{ml}$ HDL reduced Alexa-TTR-T4 uptake to $210.1 \pm 38.4(\mathrm{n}=4, \mathrm{p}=0.01)$ and $1000 \mathrm{ug} / \mathrm{ml} \mathrm{HDL}$ reduced uptake to $240 \pm 12.4(\mathrm{n}=4, \mathrm{p}=0.001)$ when compared to control cells $(344.5 \pm 9.3, n=4)$. In cells pre-reated with $500 \mathrm{ug} / \mathrm{ml} \mathrm{HDL}$ for 4 hours and then washed before uptake experiments, $500 \mathrm{ug} / \mathrm{ml}$ reduced Alexa-TTR-T4 uptake to 265.2 $\pm 9.5(\mathrm{n}=4, \mathrm{p}=0.005)$ and $1000 \mathrm{ug} / \mathrm{ml}$ HDL reduced uptake to $254.4 \pm 10.0(\mathrm{n}=4, \mathrm{p}<0.005)$ when compared to control cells (441.1 $\pm 39.5, \mathrm{n}=4$ ) (Figure 2).

Coincubation with HDL resulted in decreased uptake of TTR (Figure 2(b)) and TTR-T4 (Figure 2(c)) consistently across a 48-hour experiment.
3.3. Expression of SR-B1 in Hepatocyte Cell Lines and Knockdown of SR-B1. SR-B1 is strongly expressed by HepG2 cells [16]. Using esiRNA, SR-B1 protein was consistently knocked down to $29 \pm 8 \%\left(n=4, p=2.0 \times 10^{-7}\right)$ of mock control in HepG2 cells (Figure 3).

3.4. Effect of SR-B1 Knockdown on Alexa-TTR $( \pm$ T4) Uptake in HepG2 Cells. We then tested the effect of SR-B1 knockdown in HepG2 cells on TTR ( \pm T4) uptake. SR-B1 knockdown resulted in significantly increased uptake of TTR-T4 only at 48 hours (to $133 \%$ of uptake of mock control cells, Figure 4, $\mathrm{n}=4, \mathrm{p}<0.05)$.

\section{Discussion}

This study has demonstrated that HepG2 cells take up TTR and the TTR-T4 complex. TTR is more rapidly taken up by cells when it is bound to T4 $[3,5,8]$. T4 binding stabilises the TTR homotetramer and it is this conformation that is more readily recognised by membrane receptors [3]. Pretreatment of HepG2 cells with HDL for 4 hours results in increased uptake of Alexa-TTR-T4 (although no changes in protein level were detected following 4 hours in HDL). However, coincubation of cells with HDL and Alexa-TTR (or AlexaTTR-T4) results in reduced uptake of both Alexa-TTR and Alexa-TTR-T4. This suggests that HDL competes with and blocks TTR and TTR-T4 uptake by hepatocytes. Around 1$2 \%$ of TTR circulates in serum bound to lipoproteins [17] and HDL has previously been shown to affect uptake of unbound T4 into human fibroblasts [18] and uptake of TTR and TTRT4 by placental trophoblasts [14].

Knocking down SR-B1 expression has no significant effect on uptake of Alexa-TTR but surprisingly increases uptake of Alexa-TTR-T4. These results suggest that TTR-T4 uptake is not dependent upon SR-B1 expression but is inversely influenced by SR-B1 expression levels. A previous study also speculated that SR-B1 may be involved in TTR uptake and attempted to compare uptake in two $\mathrm{CHO}$ cell lines but were unable to show any differences in uptake, although the data was not presented in the publication [5]. However, 


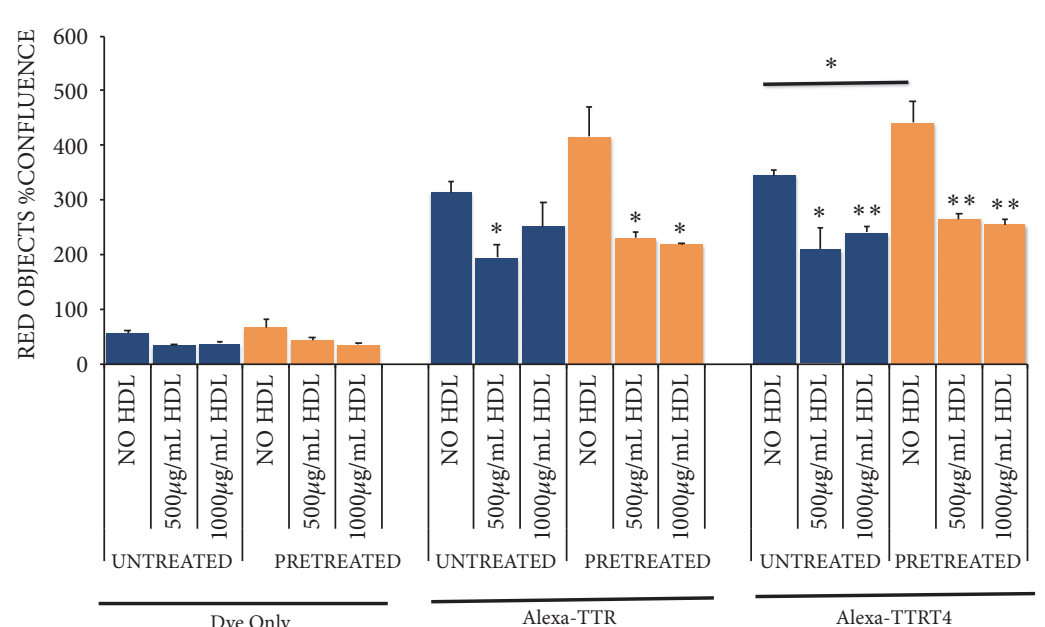

(a)

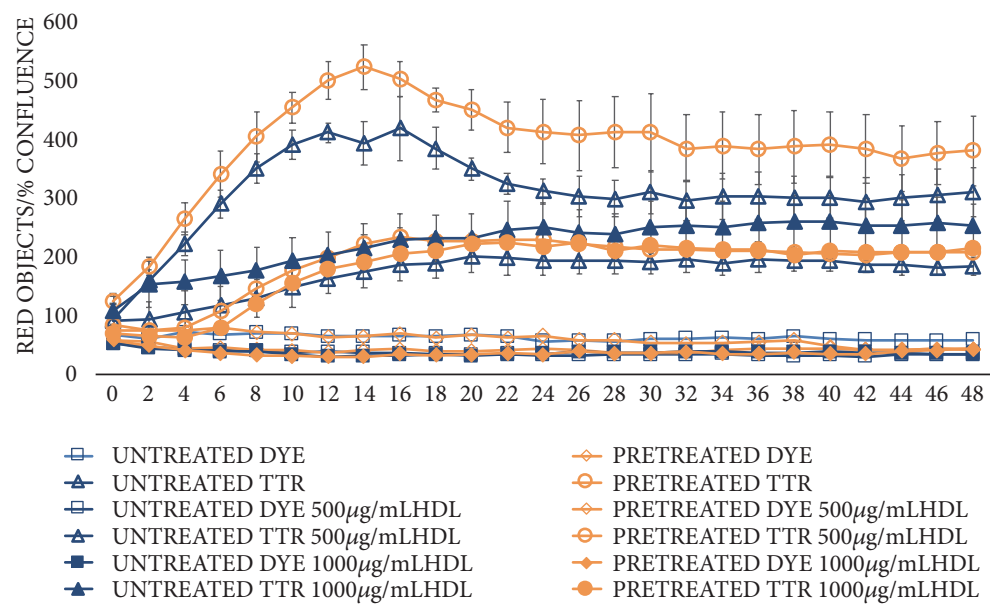

(b)

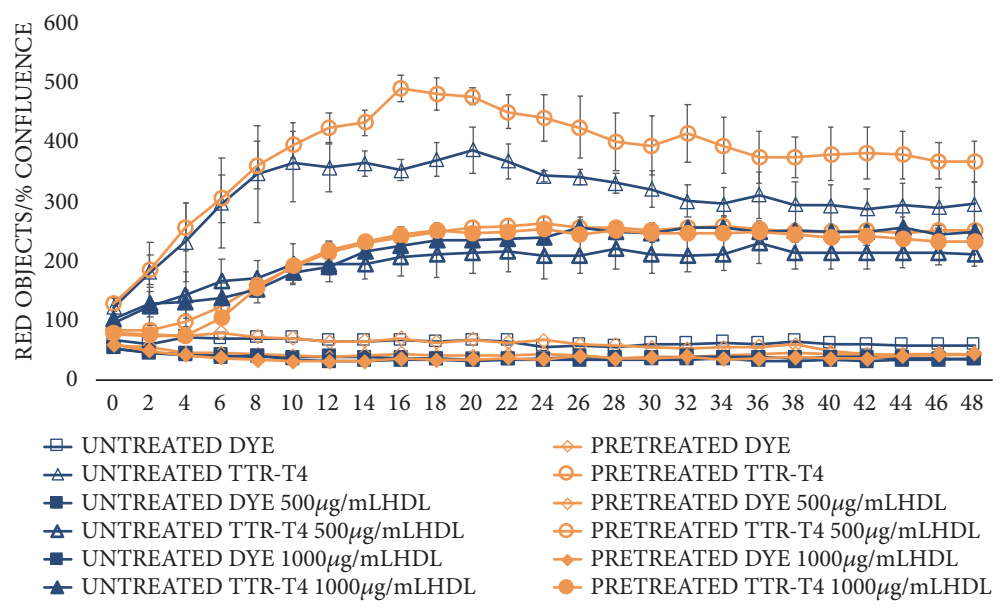

(c)

FIGURE 2: The effects of high density lipoprotein (HDL) treatment on TTR and TTR-T4 uptake in HepG2 cells. Cells were serum starved for 4 hours before uptake experiments. $500 \mathrm{ug} / \mathrm{ml} \mathrm{HDL}$ was added to the serum free medium during this 4-hour period for the HDL 'pretreated' group. Medium was removed and replaced with serum free medium containing unconjugated Alexa dye, Alexa-labelled TTR, or Alexalabelled TTR-T4 ( $\pm 500 / 1000 \mathrm{ug} / \mathrm{ml} \mathrm{HDL})$ and cells were transferred to an Essen IncuCyte incubator where intracellular fluorescence and cell confluence (\%) were measured every 2 hours. Alexa-TTR uptake is expressed as red objects/\% confluence. (a) Relative uptake of dye, Alexa-TTR, and Alexa-TTR-T4 at 24 hours. Pretreatment with $500 \mathrm{ug} / \mathrm{ml} \mathrm{HDL}$ for 4 hours resulted in greater uptake of Alexa-TTR-T4 at 24 hours $(\mathrm{p}<0.05, \mathrm{n}=4)$. Cotreatment with $500 \mathrm{ug} / \mathrm{ml}$ HDL resulted in reduced uptake of Alexa-TTR and Alexa-TTR-T4 in all conditions tested. Coincubation with $1000 \mathrm{ug} / \mathrm{ml} \mathrm{HDL}$ reduced uptake of Alexa-TTR in cells pretreated with HDL only. $1000 \mathrm{ug} / \mathrm{ml} \mathrm{HDL}$ reduced uptake of Alexa-TTR-T4 in both control and pretreated cells $(\mathrm{n}=4, * \mathrm{p}<0.05, * * \mathrm{p}<0.01)$. (b) Uptake of Alexa-TTR over 48 hours. Coincubation with HDL reduced Alexa-TTR uptake under all conditions $(n=4)$. (c) Uptake of Alexa-TTR-T4 over 48 hours. Coincubation reduced Alexa-TTRT4 uptake under all conditions $(n=4)$. 

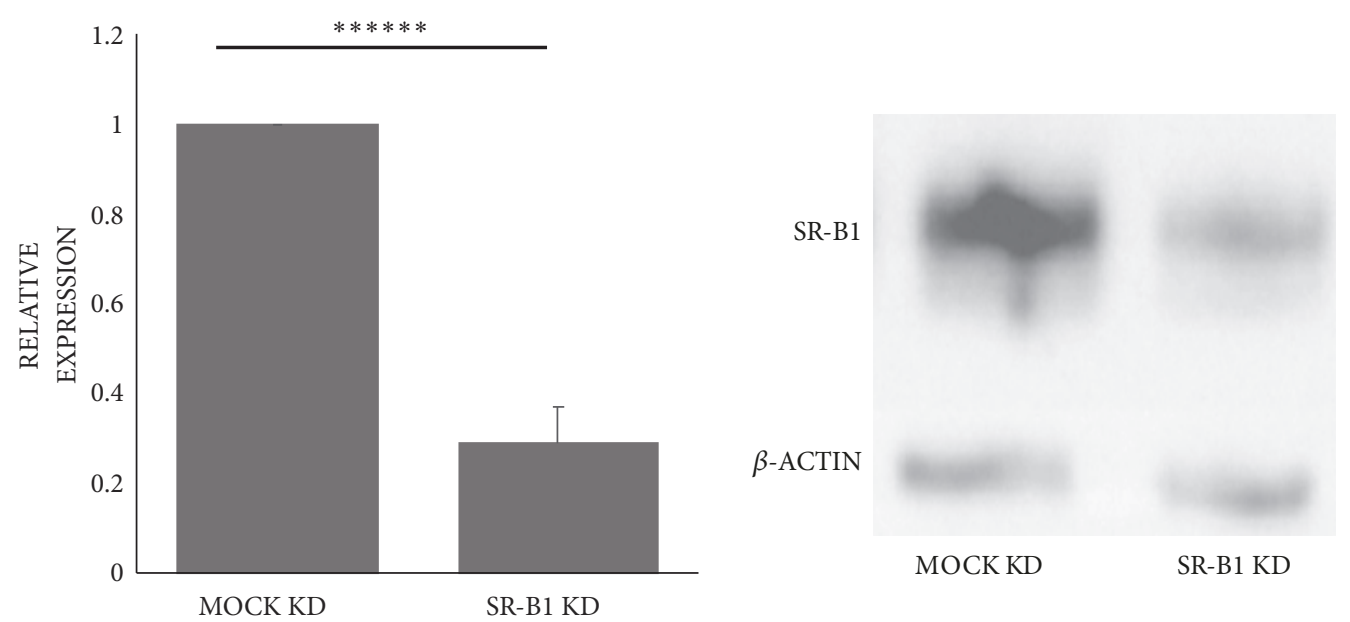

Figure 3: Scavenger receptor Class B Type 1 expression in HepG2 cells. Using esiRNA, SR-B1 levels were knocked down to $29 \pm 8 \%$ of mock knockdown (KD) control levels ( $\mathrm{n}=4, * * * * * * \mathrm{p}<0.00001)$.

in agreement with our study, the study did demonstrate that HDL was able to reduce TTR uptake in rat hepatoma cells [5]. Sousa et al. also showed that lipoproteins inhibited TTR internalisation; however they also demonstrated that uptake was not lipoprotein dependent or due to TTRlipoprotein complexes [5]. Our current study unequivocally demonstrates that, unlike trophoblasts [14], SR-B1 is not the receptor responsible for TTR uptake in hepatocytes; however TTR-T4 uptake is at least influenced by SR-B1 levels.

Aside from TTR, T4 is carried in serum by thyroxine binding globulin (TBG) and albumin. TTR-T4 uptake has previously been described in placenta [3], astrocytes [9], choroid plexus [7], retinal pigment epithelial cells [19, 20], and kidney $[4,5]$. TBG has a strong binding affinity for T4; however uptake of TBG-bound T4 has not been previously described. Albumin has a weak binding affinity for T4 and although cellular uptake of albumin is common; there is also no current evidence of uptake of albumin-T4 by cells.

Megalin is a membrane receptor that has been shown to be involved in TTR uptake by other tissues such as kidney [4] and astrocytes [9]. Megalin is not expressed by liver and specifically not in HepG2 [21] cells. Aside from SR-B1 and Megalin, no other TTR receptors have been identified to date.

The hepatocyte lipoprotein receptor involved in TTR and TTR-T4 uptake remains elusive. It may be that this process is so fundamental to TTR metabolism that the uptake mechanism is redundant and several lipoprotein transporters are capable of carrying out this important role making it difficult to identify one specifically.

The TTR uptake mechanism may be particularly sensitive to changes in local TTR levels (total of serum TTR and locally secreted TTR) making it important in cells that both secrete and endocytose TTR (e.g., placental trophoblast $[3,13]$ and hepatocytes [5]) or cells in close proximity to cells that secrete TTR (e.g., neurons/astrocytes [11]).

Coincubation with HDL decreases TTR and TTR-T4 uptake and it therefore seems possible that TTR turnover (synthesis, secretion, uptake, and degradation) is affected by diet and nutrition. The liver is very sensitive to reduced dietary protein intake and shuts down protein synthesis very rapidly. Since TTR has a very short half-life of only 2-4 days [22], serum levels of TTR are routinely used as a marker of malnutrition and have appeared since the 1970s [23]. Additionally, a reduction in serum levels of lipoproteins should lead to increased uptake of TTR by hepatocytes, leading to increased intracellular degradation. Therefore, a starvation diet/malnutrition would likely result in reduction of serum TTR levels due to both reduced TTR synthesis and increased TTR uptake and catabolism. Likewise, diet or drugs that interfere with cholesterol metabolism (such as statins [24]) may also affect TTR turnover. Any increase or decrease in circulating levels of lipoproteins would likely have an effect on TTR uptake and metabolism.

\section{Conclusion}

The data from this study concludes that TTR-T4 uptake by cultured hepatocytes is not dependent on SR-B1 expression but TTR-T4 uptake is inversely influenced by SR-B1 expression levels. Since HDL levels influence TTR-T4 uptake by liver, clearly the effect of drugs or a diet that contributes to changes in serum levels of TTR and lipoproteins will have an effect on hepatocyte TTR (and TTR-T4) uptake and subsequent turnover of TTR. Further investigation of the mechanisms of liver TTR- transport will shed more light on this important process.

\section{Data Availability}

The data used to support the findings of this study are available from the corresponding author upon request.

\section{Conflicts of Interest}

The authors declare that there are no conflicts of interest regarding the publication of this paper. 


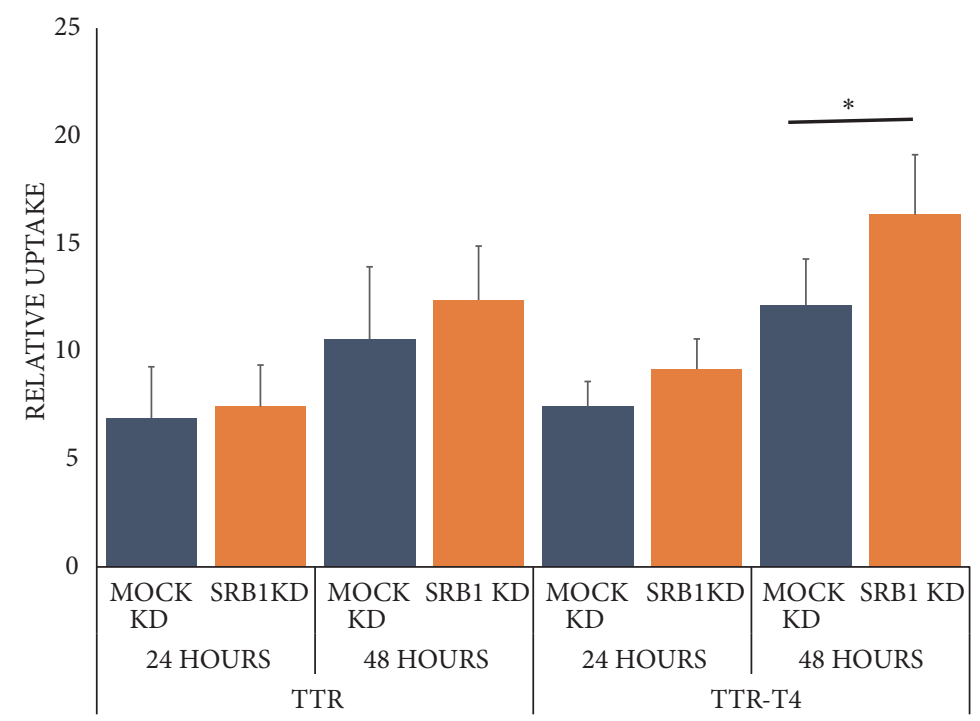

(a)

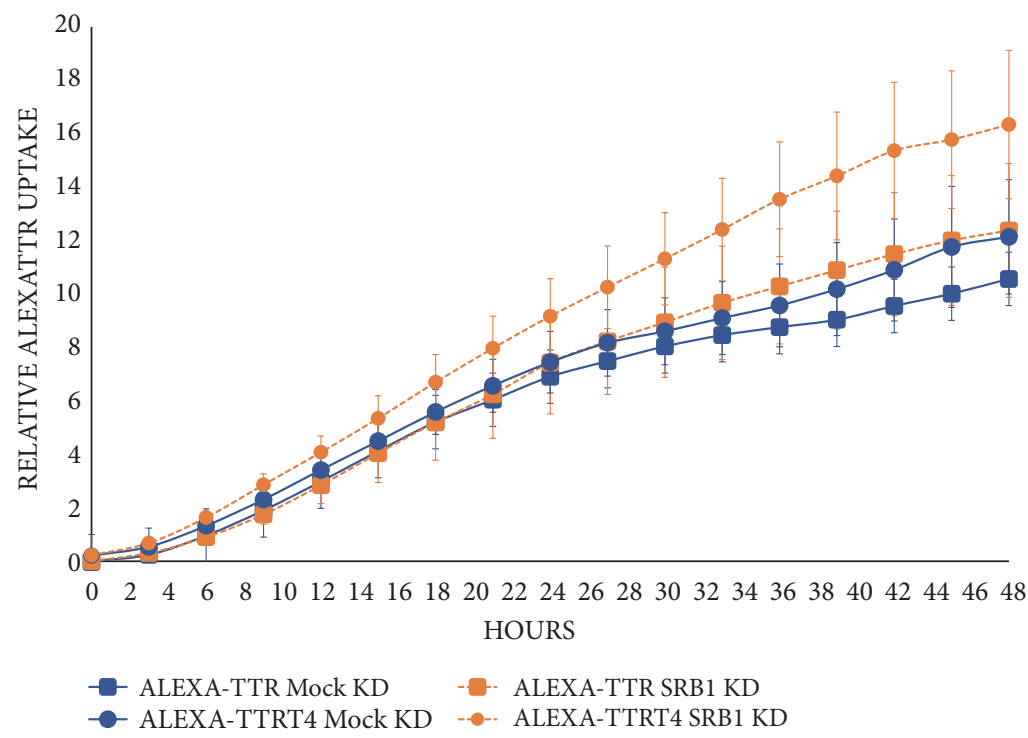

(b)

Figure 4: Scavenger receptor Class B Type 1 (SR-B1) levels affect uptake of Alexa-TTR-T4 by HepG2 cells. (a) Knockdown of SR-B1 levels (to $29 \pm 8 \%$ of mock control levels) prior to uptake experiments resulted in increased ( 133\%) uptake of Alexa-TTR-T4 at 48 hours compared to control. (b) Comparison of Alexa-TTR (square) uptake in mock control (blue) versus SR-B1 knockdown (orange) cells and of AlexaTTR-T4 (circle) uptake in mock control versus SR-B1 knockdown cells (all $\mathrm{n}=4, * \mathrm{p}<0.05)$.

\section{Acknowledgments}

This study was funded by the Science Education and Research Committee, Pathology Queensland.

\section{References}

[1] W. E. Visser, E. C. H. Friesema, J. Jansen, and T. J. Visser, "Thyroid hormone transport in and out of cells," Trends in Endocrinology \& Metabolism, vol. 19, no. 2, pp. 50-56, 2008.

[2] L. Recant and D. S. Riggs, "Thyroid function in nephrosis," The Journal of Clinical Investigation, vol. 31, no. 8, pp. 789-797, 1952.

[3] K. A. Landers, B. D. McKinnon, H. Li, V. N. Subramaniam, R. H. Mortimer, and K. Richard, "Carrier-mediated thyroid hormone transport into placenta by placental transthyretin," The Journal of Clinical Endocrinology \& Metabolism, vol. 94, no. 7, pp. 26102616, 2009.

[4] M. M. Sousa, A. G. W. Norden, C. Jacobsen et al., "Evidence for the role of megalin in renal uptake of transthyretin," The Journal of Biological Chemistry, vol. 275, no. 49, pp. 38176-38181, 2000.

[5] M. M. Sousa and M. J. Saraiva, "Internalization of transthyretin. Evidence of a novel yet unidentified receptor-associated protein (RAP)-sensitive receptor," The Journal of Biological Chemistry, vol. 276, no. 17, pp. 14420-14425, 2001.

[6] M. Vieira and M. J. Saraiva, "Transthyretin: A multifaceted protein," Biomolecular Concepts, vol. 5, no. 1, pp. 45-54, 2014.

[7] J. Herbert, J. N. Wilcox, K.-T. C. Pham et al., "Transthyretin: A choroid plexus-specific transport protein in human brain. The 
1986 S. Weir Mitchell Award," Neurology, vol. 36, no. 7, pp. 900911, 1986.

[8] C. M. Divino and G. C. Schussler, "Receptor-mediated uptake and internalization of transthyretin," The Journal of Biological Chemistry, vol. 265, no. 3, pp. 1425-1429, 1990.

[9] C. M. Divino and G. C. Schussler, "Transthyretin receptors on human astrocytoma cells," The Journal of Clinical Endocrinology \& Metabolism, vol. 71, no. 5, pp. 1265-1268, 1990.

[10] N. A. Kassem, R. Deane, M. B. Segal, and J. E. Preston, "Role of transthyretin in thyroxine transfer from cerebrospinal fluid to brain and choroid plexus," American Journal of PhysiologyRegulatory, Integrative and Comparative Physiology, vol. 291, no. 5, pp. R1310-R1315, 2006.

[11] A. Zawişlak, P. Jakimowicz, J. A. McCubrey, and D. Rakus, "Neuron-derived transthyretin modulates astrocytic glycolysis in hormone-independent manner," Oncotarget, vol. 8, no. 63, pp. 106625-106638, 2017.

[12] M. A. Gertz, M. D. Benson, P. J. Dyck et al., "Diagnosis, Prognosis, and Therapy of Transthyretin Amyloidosis," Journal of the American College of Cardiology, vol. 66, no. 21, pp. 24512466, 2015.

[13] B. McKinnon, H. Li, K. Richard, and R. Mortimer, "Synthesis of thyroid hormone binding proteins transthyretin and albumin by human trophoblast," The Journal of Clinical Endocrinology \& Metabolism, vol. 90, no. 12, pp. 6714-6720, 2005.

[14] K. A. Landers, H. Li, R. H. Mortimer, D. S. A. McLeod, M. C. d'Emden, and K. Richard, "Transthyretin uptake in placental cells is regulated by the high-density lipoprotein receptor, scavenger receptor class B member 1," Molecular and Cellular Endocrinology, vol. 474, pp. 89-96, 2018.

[15] L. P. Ganesan, J. M. Mates, A. M. Cheplowitz et al., "Scavenger receptor $\mathrm{B} 1$, the HDL receptor, is expressed abundantly in liver sinusoidal endothelial cells," Scientific Reports, vol. 6, no. 1, 2016.

[16] D. Rhainds, P. Bourgeois, G. Bourret, K. Huard, L. Falstrault, and L. Brissette, "Localization and regulation of SR-BI in membrane rafts of HepG2 cells," Journal of Cell Science, vol. 117, no. 15, pp. 3095-3105, 2004.

[17] M. M. Sousa, L. Berglund, and M. J. Saraiva, "Transthyretin in high density lipoproteins: association with apolipoprotein A-I," Journal of Lipid Research, vol. 41, no. 1, pp. 58-65, 2000.

[18] S. Benvenga, S. Alesci, and F. Trimarchi, "High-density lipoprotein-facilitated entry of thyroid hormones into cells: A mechanism different from the low-density lipoprotein-facilitated entry," Thyroid, vol. 12, no. 7, pp. 547-556, 2002.

[19] A. Jaworowski, Z. Fang, T. F. Khong, and R. C. Augusteyn, "Protein synthesis and secretion by cultured retinal pigment epithelia," BBA - General Subjects, vol. 1245, no. 1, pp. 121-129, 1995.

[20] D. E. Ong, J. T. Davis, W. T. O’Day, and D. Bok, “Synthesis and secretion of retinol-binding protein and transthyretin by cultured retinal pigment epithelium," Biochemistry, vol. 33, no. 7, pp. 1835-1842, 1994.

[21] A. A. Akour, M. J. Kennedy, and P. M. Gerk, "The role of megalin in the transport of gentamicin across BeWo cells, an in vitro model of the human placenta," The American Association of Pharmaceutical Scientists Journal, vol. 17, no. 5, pp. 1193-1199, 2015.

[22] A. Makover, H. Moriwaki, R. Ramakrishnan, M. J. M. Saraiva, W. S. Blaner, and S. Goodman DeWitt, "Plasma transthyretin. Tissue sites of degradation and turnover in the rat," The Journal of Biological Chemistry, vol. 263, no. 18, pp. 8598-8603, 1988.
[23] G. Devoto, F. Gallo, C. Marchello et al., "Prealbumin serum concentrations as a useful tool in the assessment of malnutrition in hospitalized patients," Clinical Chemistry, vol. 52, no. 12, pp. 2281-2285, 2006.

[24] E. S. Istvan and J. Deisenhofer, "Structural mechanism for statin inhibition of HMG-CoA reductase," Science, vol. 292, no. 5519, pp. 1160-1164, 2001. 


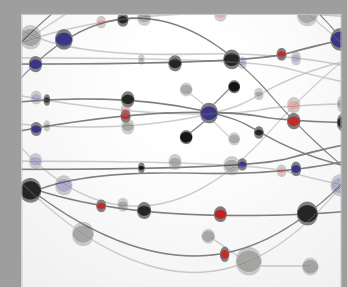

The Scientific World Journal
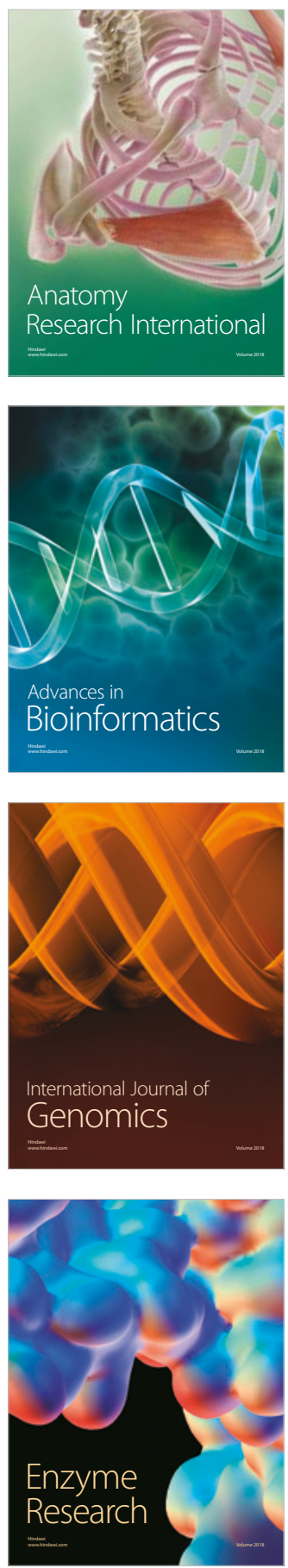
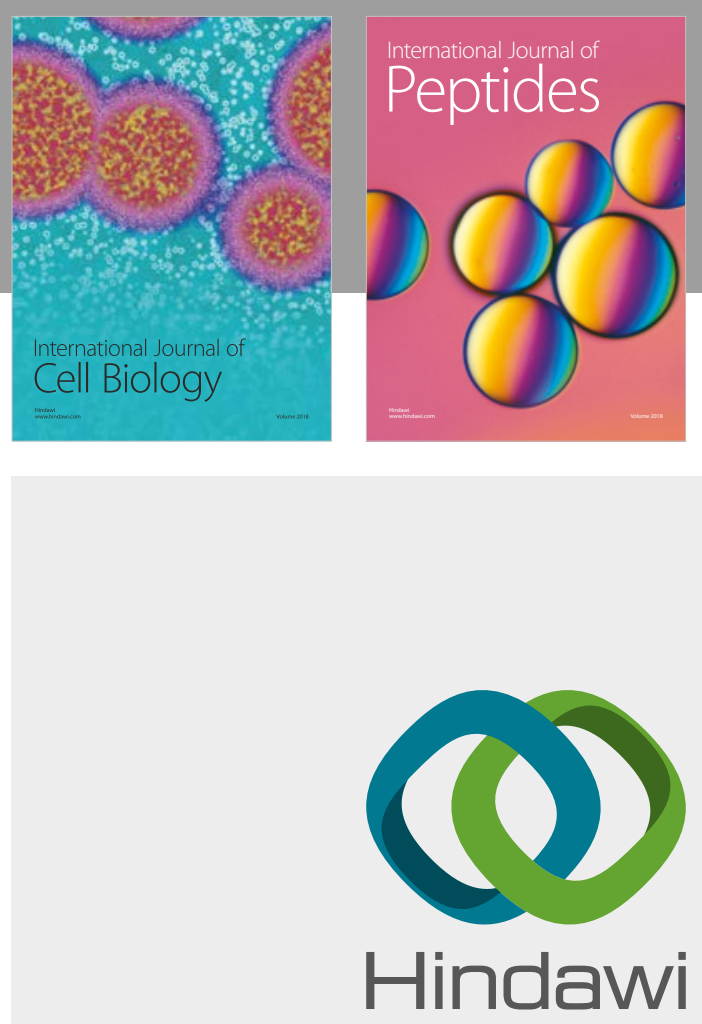

Submit your manuscripts at

www.hindawi.com
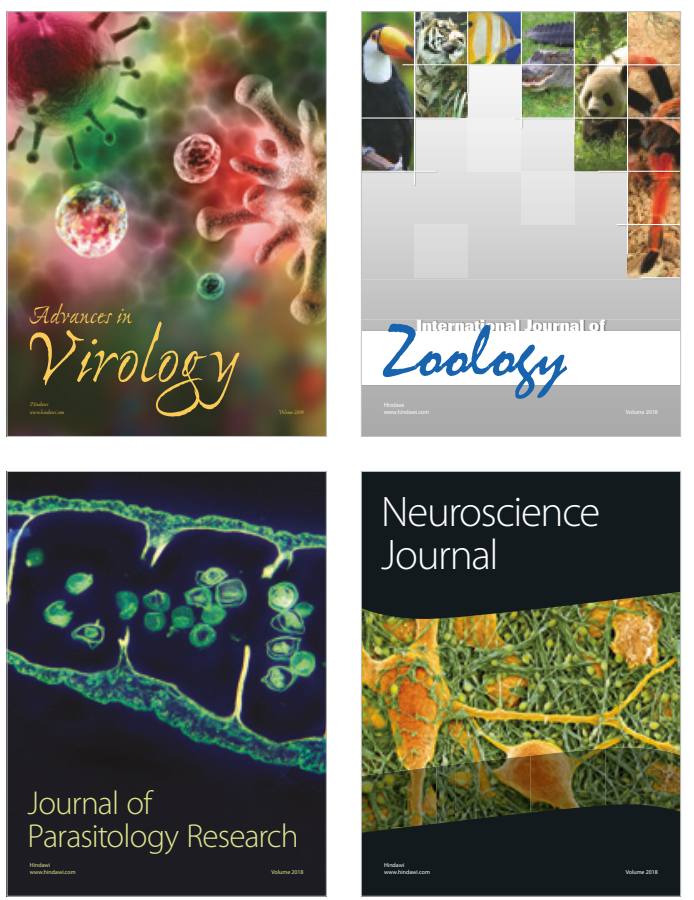
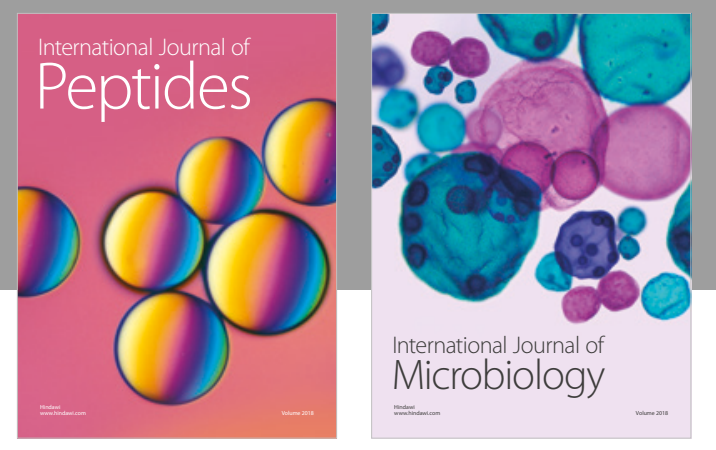

nternational Journal of Microbiology
Journal of
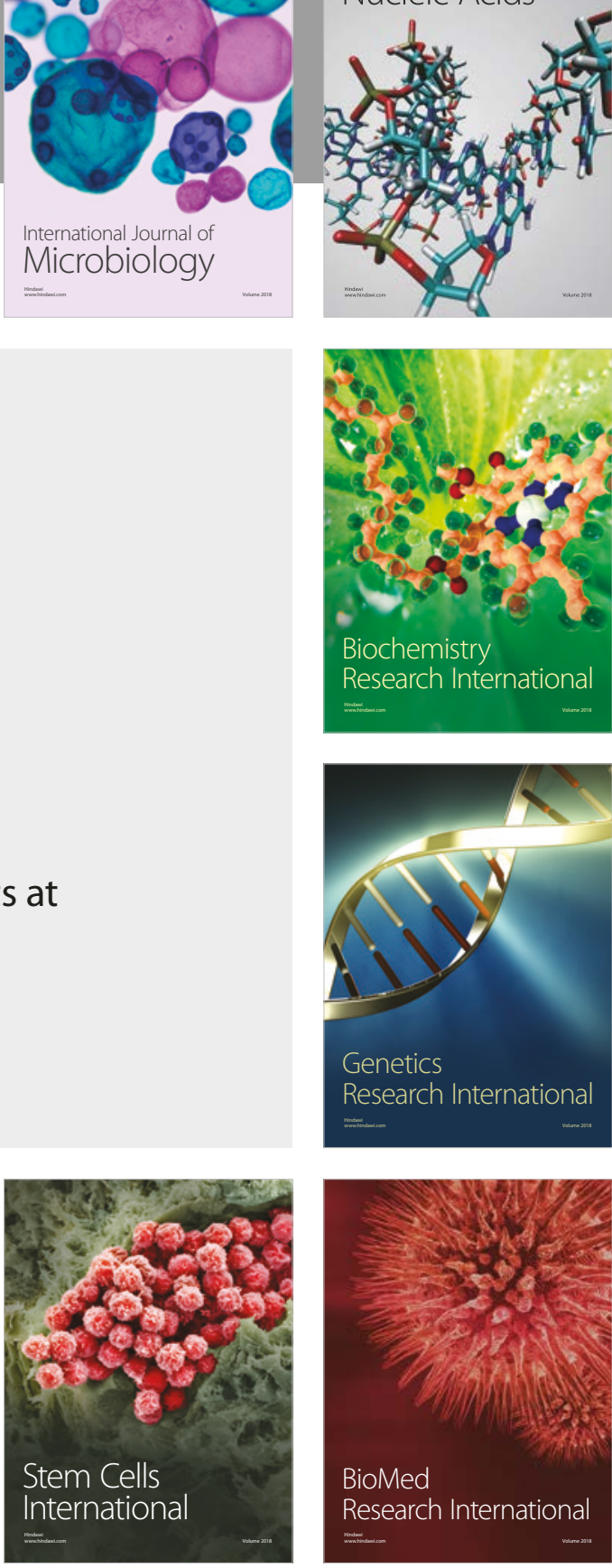
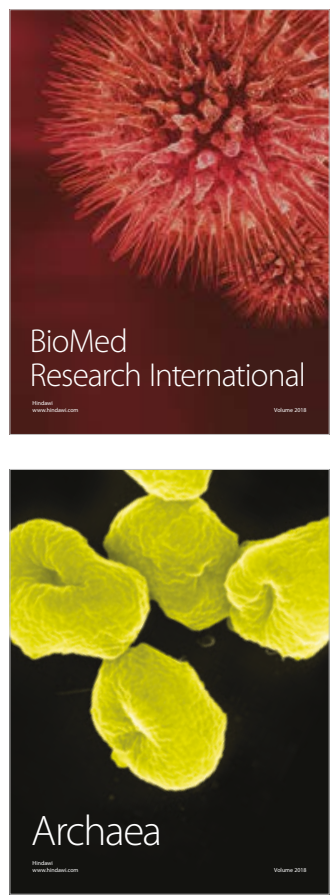